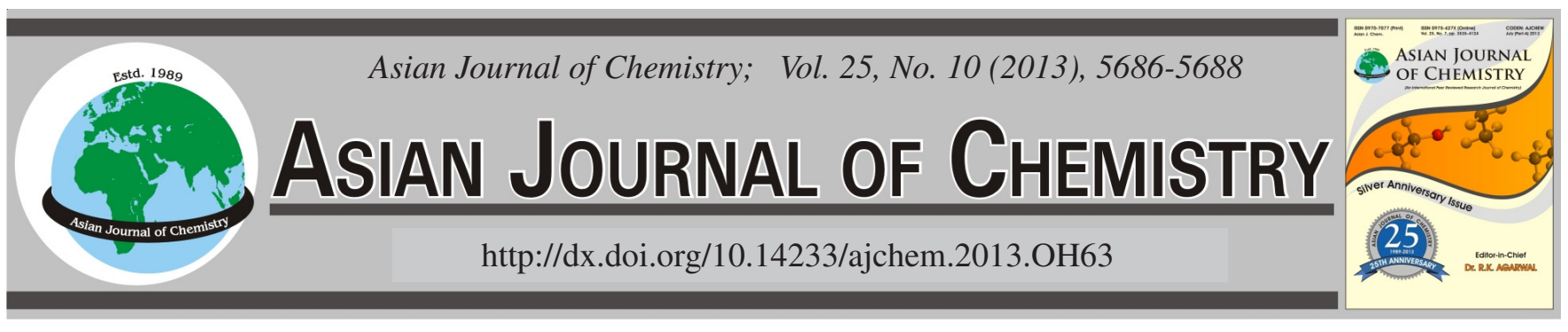

\title{
Flammability Performance of Ethylene-propylene-diene-terpolymer/ Polypropylene-Based Thermoplastic Elastomers $\dagger$
}

\author{
Hongdian Lu*, Jingsong Xie, Yaqing Ma, Hui He and Haotian Wu
}

Department of Chemical and Materials Engineering, Hefei University, Hefei 230022, Anhui Province, P.R. China

*Corresponding author: E-mail: luhdo@hfuu.edu.cn

The synergistic effect of organically modified montmorillonite on flammability properties and thermal stability of magnesium hydroxide and red phosphorous flame retardant ethylene-propylene-diene-terpolymer/polypropylene thermoplastic elastomers was investigated. The results revealed that organically modified montmorillonite could improve fire safety of thermoplastic elastomer/magnesium hydroxide/ red phosphorus [TPE/MH/RP] materials by promoting the formation of compact and integrated chars.

Key Words: Ethylene-propylene-diene-terpolymer, Polypropylene, Thermoplastic elastomers, Flame retardant.

ᄂ $-\ldots-\ldots-\ldots-\ldots-\ldots-\ldots-\ldots-\ldots-\ldots-\ldots-\ldots$

\section{INTRODUCTION}

Thermoplastic elastomers (TPEs) have attracted considerable technologically interest because they combine the physical properties of elastomers with the process ability of thermoplastic polymers ${ }^{1}$. Because thermoplastic elastomers are inherent flammable, it is important to improve their flame retardancy. Incorporation of magnesium hydroxide $(\mathrm{MH})$ and phosphorouscontaining compounds into polymeric materials is the common way to protect them from fire and heat ${ }^{2}$. However, the effective flame retardancy has to be achieved at the expense of deterioration of the material mechanical properties due to the high global loading of magnesium hydroxide. The partial replacement of magnesium hydroxide by red phosphorus (RP) has led this flame retardant system exhibit good synergy and imparted the materials with improved flame retardancy ${ }^{3}$. For the past decades, combination of montmorillonite (MMT) with traditional flame retardants to improve the material properties concurrently, such as reduced flammability and permeability, improved mechanical properties and thermal stability has been studied intensively ${ }^{4}$. The complicated chemical and/or physical mechanisms are responsible for the improvements. In this paper, MH/RP/MMT flame retardant thermoplastic elastomers were prepared by melt blending. The effect of the combined flame retardants on improving flame retardancy of the materials was also reported.

\section{EXPERIMENTAL}

Flame retardant ethylene-propylene-diene-terpolymer/ polypropylene [EPDM/PP]-based thermoplastic elastomers were melt compounded of EPDM/PP (60/40 by weight) with desired amount of flame retardants, magnesium hydroxide and red phosphorous microencapsulated with melamine-formaldehyde resins (MRP) in a Brabender mixer at $180^{\circ} \mathrm{C}$ for $10 \mathrm{~min}$, using 5 phr (part of reagent per hundred of EPDM) SP-1045 (Phenol-formaldehyde resin) in combination with $1 \mathrm{phr} \mathrm{SnCl}_{2}$ and $1.5 \mathrm{phr} \mathrm{ZnO}$ as curing agent systems. To obtain organically modified montmorillonite (OMT) containing thermoplastic elastomers (NTPEs), PP/MAPP (maleated polypropylene)/ OMT $(85 / 15 / 10$ by weight) masterbatch was firstly extruded using a twin-screw extruder at $160-180^{\circ} \mathrm{C}$. The strands were then pelletized and mixed with EPDM and flame retardant additives in the mixer for $10 \mathrm{~min}$. The formulations are shown in Table- 1 .

\section{RESULTS AND DISCUSSION}

Thermal stability: Thermal stability of thermoplastic elastomers was carried out by TGA (Fig. 1). TPE0 displays a one-step degradation process, starting at $493{ }^{\circ} \mathrm{C}\left(\mathrm{T}_{10 \%}\right.$, the temperature point at which $10 \mathrm{wt} \%$ thermal degradation occurs) with $\mathrm{T}_{\max }$ (the maximum weight loss temperature) at $459^{\circ} \mathrm{C}$ and completing at $500{ }^{\circ} \mathrm{C}$ with $2.5 \%$ residual char. An apparent two-step degradation process is observed for the selected samples, TPE1 and TPE4. The first degradation in the temperature $320-450{ }^{\circ} \mathrm{C}$ is attributed to the endothermic decomposition of magnesium hydroxide, while the second is assigned to the degradation of polymers and the degradation of TPE0 over $450{ }^{\circ} \mathrm{C}$ is effectively retarded by the presence of magnesium

$†$ Presented to the 6th China-Korea International Conference on Multi-functional Materials and Application, 22-24 November 2012, Daejeon, Korea 


\begin{tabular}{|c|c|c|c|c|c|c|c|}
\hline \multicolumn{8}{|c|}{$\begin{array}{c}\text { TABLE-1 } \\
\text { COMPOSITION AND FLAMMABILITY PERFORMANCE } \\
\text { OF FLAME RETARDANT TPEs }{ }^{\mathrm{a}}\end{array}$} \\
\hline \multirow[b]{2}{*}{$\begin{array}{l}\text { Sample } \\
\text { code }\end{array}$} & \multicolumn{5}{|c|}{ Composition (g) } & \multirow[b]{2}{*}{ LOI } & \multirow[b]{2}{*}{$\begin{array}{c}\text { UL-94 } \\
\text { Testing }\end{array}$} \\
\hline & EPDM & PP & $\begin{array}{l}\text { PP/MAPP/OMT } \\
\text { Master batch } \\
(85 / 15 / 10)\end{array}$ & $\mathrm{MH}$ & MRP & & \\
\hline TPE0 & 60 & 40 & & & & 19 & Fail \\
\hline TPE1 & 60 & 40 & & 100 & & 32 & Fail \\
\hline TPE2 & 60 & 40 & & 130 & & 35 & Fail \\
\hline TPE3 & 60 & 40 & & 140 & & 36 & Fail \\
\hline TPE4 & 60 & 40 & & 160 & & 39.5 & $\mathrm{~V}-0$ \\
\hline TPE5 & 60 & 40 & & 90 & 10 & 34.5 & Fail \\
\hline TPE6 & 60 & 40 & & 86 & 14 & 33.5 & Fail \\
\hline TPE7 & 60 & 40 & & 82 & 18 & 32.5 & $\mathrm{~V}-0$ \\
\hline TPE8 & 60 & 40 & & 78 & 22 & 32 & $\mathrm{~V}-0$ \\
\hline NTPE0 & 60 & & 40 & & & 20 & Fail \\
\hline NTPE1 & 60 & & 40 & 130 & & 36 & Fail \\
\hline NTPE2 & 60 & & 40 & 140 & & 37 & Fail \\
\hline NTPE3 & 60 & & 40 & 150 & & 38.5 & Fail \\
\hline NTPE4 & 60 & & 40 & 155 & & 40.5 & $\mathrm{~V}-0$ \\
\hline NTPE5 & 60 & & 40 & 90 & 10 & 34.5 & Fail \\
\hline NTPE6 & 60 & & 40 & 86 & 14 & 33 & $\mathrm{~V}-0$ \\
\hline NTPE7 & 60 & & 40 & 82 & 18 & 32.5 & $\mathrm{~V}-0$ \\
\hline
\end{tabular}

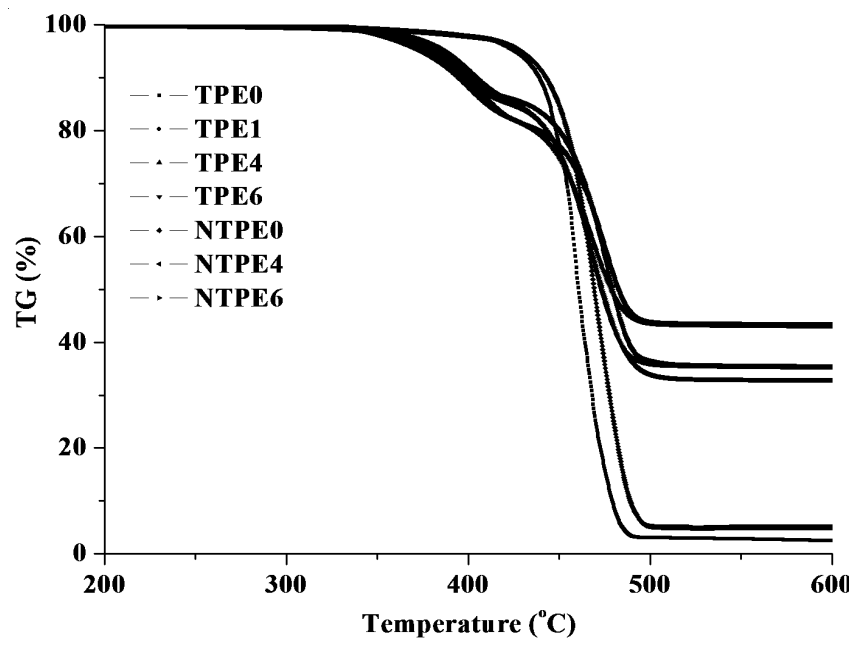

Fig. 1. TGA curves of flame retardant TPEs

hydroxide. Organically modified montmorillonite (OMT) has a positive effect with magnesium hydroxide in the improvement of thermal stability; NTPE0 and NTPE4 samples exhibit increased $\mathrm{T}_{1 \max }, \mathrm{T}_{2 \max }$ and char yields compared to TPE0 and TPE4, respectively. The similar results have been found in MH/RP/OMT flame retardant NTPE6 sample.

Flammability studies: A set of fire related parameters obtained from the MCC including heat release capacity, peak heat release rate (PHRR), total heat release, the temperature at peak heat release rate $\left(\mathrm{T}_{\mathrm{p}}\right)$ and the reduction in peak heat release rate (Reduct-MCC, $100 \times\left[\mathrm{PHRR}_{(\mathrm{N}) T \mathrm{TPE} s}-\mathrm{PHRR}_{\mathrm{TPE} 0}\right) /$ $\mathrm{PHRR}_{\text {TPEO }}$ are listed in Table- 2 and the heat release rate curves of flame retarded TPEs are shown in Fig. 2. All the parameters of thermoplastic elastomers with magnesium hydroxide alone, heat release capacity, peak heat release rate and total heat release decrease gradually with increasing magnesium hydroxide loadings, while $\mathrm{T}_{\mathrm{p}}$-MCC shifts to a higher temperature slightly (Fig. 2a). As expected, the limited oxygen index value is increased from 19 of TPE0 to 39.5 of TPE4 and UL 94 V-0

\begin{tabular}{cccccc}
\multicolumn{6}{c}{ TABLE-2 } \\
MCC DATA OF FLAME RETARDANT TPEs \\
\hline Sample & $\begin{array}{c}\text { HRC } \\
(\mathrm{J} / \mathrm{g} \cdot \mathrm{k})\end{array}$ & $\begin{array}{c}\text { PHRR } \\
(\mathrm{W} / \mathrm{g})\end{array}$ & $\begin{array}{c}\text { THR } \\
(\mathrm{kJ} / \mathrm{g})\end{array}$ & $\begin{array}{c}\mathrm{T}_{\mathrm{p}} \\
\left({ }^{\circ} \mathrm{C}\right)\end{array}$ & $\begin{array}{c}\text { Reduct- } \\
\text { MCC }(\%)\end{array}$ \\
\hline TPE0 & 1171 & 1165 & 44 & 494 & NA \\
TPE1 & 678 & 673 & 23 & 495 & 42 \\
TPE3 & 545 & 541 & 19 & 493 & 53 \\
TPE4 & 477 & 475 & 17 & 497 & 59 \\
TPE5 & 643 & 639 & 22 & 498 & 45 \\
TPE6 & 670 & 666 & 23 & 498 & 43 \\
TPE7 & 662 & 658 & 23 & 496 & 43 \\
NTPE2 & 562 & 559 & 18 & 494 & 52 \\
NTPE4 & 478 & 475 & 17 & 499 & 59 \\
NTPE5 & 591 & 586 & 22 & 496 & 50 \\
NTPE6 & 609 & 605 & 22 & 497 & 48 \\
NTPE7 & 621 & 616 & 23 & 498 & 47 \\
\hline
\end{tabular}

classification is achieved at TPE4. NTPE4 exhibits the similar MCC feature to that of TPE4, but the replacement of polypropylene with $\mathrm{PP} / \mathrm{MAPP} / \mathrm{OMT}$ masterbatch imparts the material with increased flame retardancy in terms of limited oxygen index. Fig. 2B shows the heat release rate curves of MH/MRP and MH/RP/OMT flame retarded TPEs. The heat release rate curves are much the same for all the samples, but NTPE6 and 7 shows higher Reduct-MCC compared to TPE 6 and 7. Meanwhile, the limited oxygen index values decrease with increasing RP/MH ratios for TPE and NTPE samples and the V-0 classification is achieved at TPE7 with MH/RP ratio of $82 / 18$ while NTPE6 with a higher ratio of $86 / 14$. The results indicate that too much MRP will deteriorate the improvement of material flammability properties due to its own inherent combustibility and there is an optimum amount of MRP should be present in different flame retardant systems.
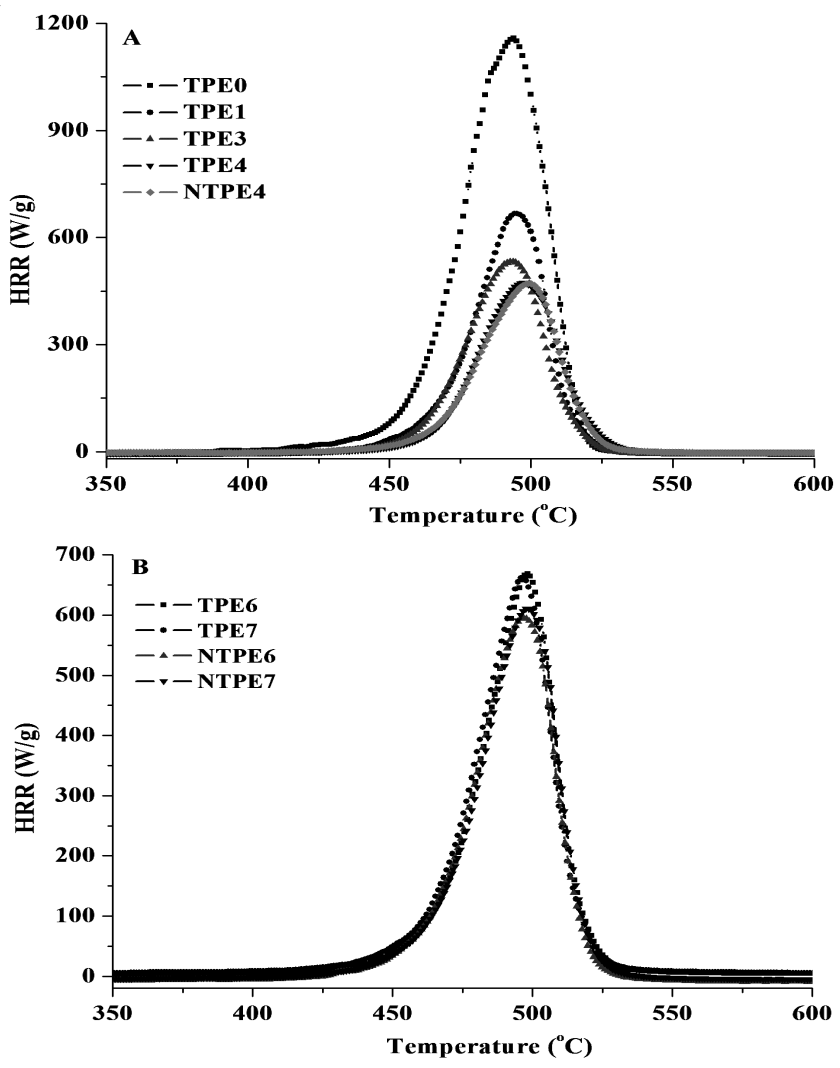

Fig. 2. HRR curves of flame retardant TPEs 
SEM studies: The physical properties of the char have an important role in the material fire performance. TPE1 leaves a loose char with poor mechanical properties (Fig. $3 \mathrm{~A}_{1}$ and $\mathrm{A}_{2}$ ), while a more compact and rigid char bestrewed with holes and cracks is observed in TPE7 (Fig. $3 \mathrm{~B}_{1}$ and $\mathrm{B}_{2}$ ). For sample NTPE6, an integrated and tight char is left (Fig. $3 \mathrm{C}_{1}$ and $\mathrm{C}_{2}$ ), which provides the underlying materials better thermal protection than other TPE1 or TPE7. Two things, the segregation and Hofmann degradation of organically modified montmorillonite, are mainly taken into consideration for the difference. The first is that acidic sites in the aluminosilicate $\left(\mathrm{LS}^{-+} \mathrm{H}\right)$ generated from the Hofmann degradation of organically modified montmorillonite accelerate the endothermic decomposition of magnesium hydroxide. On the other hand, immigration of clay within polymeric matrix to resemble on the sample surface will be promoted by the water vapour in addition to the degradation polymer products and thus the well-known carbonaceous-silicate barrier will generate. As a result, both the transfer of water vapour and phosphorus vapour from melamine-formaldehyde resins will be impeded by the segregation, which is beneficial to ensure the completing oxidation to form the glassy phosphoric acid coating on the substrate.
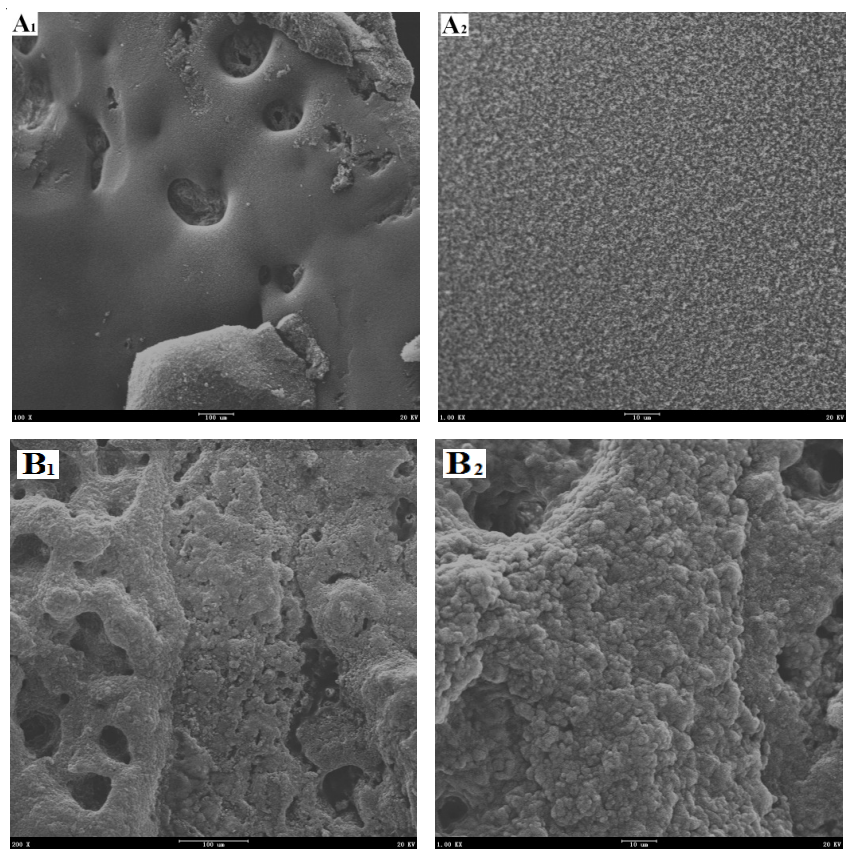
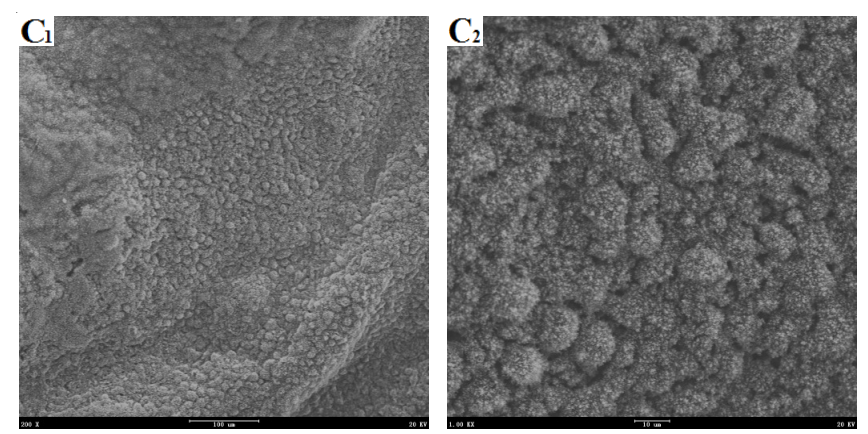

Fig. 3. SEM micrographs of the residual chars

\section{Conclusion}

Melamine-formaldehyde resins is a good synergist in improving flame retardancy of TPE/MH composites; organically modified montmorillonite has crucial importance on the interaction with MH/MRP by increasing the integration and mechanical strength of the char, which is favourable to improve flammability performance of the materials.

\section{ACKNOWLEDGEMENTS}

The work was financially supported by the National Natural Science Foundation of China (No. 51276054, 50903080).

\section{REFERENCES}

1. P. Chakraborty, A. Ganguly, S. Mitra and A.K. Bhowmick, J. Mater. Sci., 43, 6167 (2008).

2. A.I. Balabanovich, D. Pospiech and A. Korwitz, Polym. Degrad. Stab., 94, 355 (2009).

3. Z.Z. Wang, G.S. Wu, Y. Hu, Y. Ding, K.L. Hu and W.C. Fan, Polym. Degrad. Stab., 77, 427 (2002).

4. B.B. Marosfoi, S. Garas, B. Bodzay, F. Zubonyai and G. Marosi, Polym. Adv. Technol., 19, 693 (2008). 